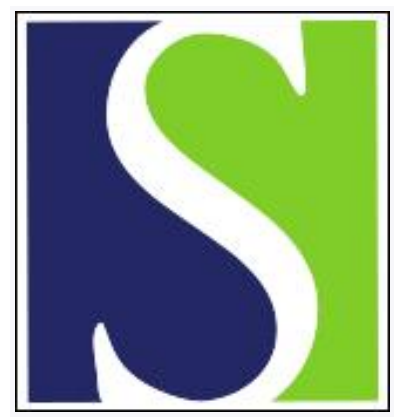

Scand J Work Environ Health 2020;46(2):177-187

https://doi.org/10.5271/sjweh.3847

Published online: 21 Aug 2019, Issue date: 01 Mar 2020

Breast cancer specialists' perspective on their role in their patients' return to work: A qualitative study

by Lamort-Bouché M, Péron J, Broc G, Kochan A, Jordan C, Letrilliart L, Fervers B, Fassier J-B; FASTRACS Group

This qualitative study showed that breast cancer specialists have varied perspectives and experiences in supporting their patients' return to work (RTW). Even when they are interested, they have little time to devote to it. They emphasize patients' motivation and fail to identify several RTW barriers, particularly workplace factors that may impede return to work.

Affiliation: Université Lyon, Université Claude Bernard Lyon 1, Unité Mixte de Recherche Epidémiologique et de Surveillance Transport Travail Environnement, UMRESTTE UMR T 9405, 8 Avenue Rockefeller, F-69008 Lyon, France. marion.lamort-bouche@univ-lyon1.fr

Refers to the following text of the Journal: 2012;38(2):144-154

The following article refers to this text: 2021;47(2):91-93

Key terms: breast cancer; Breast cancer specialist; breast cancer survivor; cancer; general practioner; intervention mapping; occupational physician; oncology; patient; psychosocial; qualitative study; return to work; RTW

This article in PubMed: www.ncbi.nlm.nih.gov/pubmed/31433060

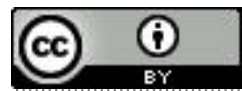




\title{
Breast cancer specialists' perspective on their role in their patients' return to work: A qualitative study
}

\author{
by Marion Lamort-Bouché, MD, PhDc, ${ }^{1,2}$ Julien Péron, MD, PhD, 3,4,5 Guillaume Broc, PhD, ${ }^{1}$ Angélika Kochan, MD, ${ }^{2}$ \\ Clémentine Jordan, MD, ${ }^{2}$ Laurent Letrilliart, MD, PhD, ${ }^{2,6}$ Béatrice Fervers, MD, PhD, 7,8 Jean-Baptiste Fassier, MD, PhD, 1,9 \\ and the FASTRACS study group ${ }^{10}$
}

\begin{abstract}
Lamort-Bouché M, Péron J, Broc G, Kochan A, Jordan C, Letrilliart L, Fervers B, Fassier J-B, FASTRACS study group. Breast cancer specialists' perspective on their role in their patients' return to work: A qualitative study. Scand J Work Environ Health. 2020;46(2):177-187. doi:10.5271/sjweh.3847
\end{abstract}

Objectives This study aimed to explore the views of breast cancer (BC) specialists as to their role in the returnto-work (RTW) process of their BC patients.

Methods A qualitative study using semi-structured interviews was conducted in a sample of 20 BC specialists selected according to age, gender, medical specialty (medical oncology, radiation oncology, gynecological surgery), and healthcare organization (regional cancer center, university or private hospital). All interviews were audiotaped and transcribed for qualitative thematic content analysis.

Results BC specialists had heterogeneous representations and practices regarding their role in their patients' RTW process, ranging from non-involvement to frequent discussion. Most BC specialists had concerns regarding the "right time and right way" to address patient's RTW. They hardly mentioned workplace and job factors as potential barriers but rather stressed motivation. The main reported barriers to involvement in the RTW process were lack of time, lack of knowledge, lack of skills, and a professional attitude exclusively focused on cancer care issues.

Conclusion While our study showed varying representations and practices among BC specialists, participants consistently identified barriers in supporting BC survivors' RTW. The results will guide the development of an intervention to facilitate the role of BC specialists in the RTW process as part of a multicomponent intervention to facilitate BC survivors' RTW.

Key terms breast cancer survivor; general practioner; intervention mapping; psychosocial, occupational physician; oncology; RTW.

1 Université Lyon, Université Claude Bernard Lyon 1, Unité Mixte de Recherche Epidémiologique et de Surveillance Transport Travail Environnement, UMRESTTE UMR T 9405, Lyon, France.

2 Université Lyon, Université Claude Bernard Lyon 1, Collège Universitaire de Médecine Générale, Lyon, France.

3 CNRS, UMR 5558, Laboratoire de Biométrie et Biologie Evolutive, Equipe Biostatistique-Santé, Université Lyon 1, Villeurbanne, France.

4 Hospices Civils de Lyon, Service de Biostatistique et Bioinformatique, Lyon, France.

5 Institut de Cancérologie des Hospices Civils de Lyon, Oncology Department, Pierre-Benite, France.

6 Univ Lyon, Université Claude Bernard Lyon 1, Health Services and Performance Research, HESPER, EA 7425, Lyon, France

7 INSERM UA 08 Radiations: Défense, Santé, Environnement, Lyon, France.

8 Département Cancer et Environnement, Centre Léon Bérard, Lyon, France.

9 Univ. Lyon, Service de Médecine et Santé au Travail, Hospices Civils de Lyon, Lyon, France.

10 FASTRACS study group: Guillaume Broc, Julien Carretier, Jean-Baptiste Fassier, Béatrice Fervers, Laure Guittard, Marion Lamort-Bouché, Laurent Letrilliart, Julien Péron, Sabrina Rouat, Philippe Sarnin

Correspondence to: Dr Marion Lamort-Bouché, Université Lyon, Université Claude Bernard Lyon 1, Unité Mixte de Recherche Epidémiologique et de Surveillance Transport Travail Environnement, UMRESTTE UMR T 9405, 8 Avenue Rockefeller, F-69008 Lyon, France. [E-mail: marion. lamort-bouche@univ-lyon1.fr] 
Breast cancer $(\mathrm{BC})$ is the most common cancer in women worldwide (1), with good prognosis and 5-year survival rates exceeding $80 \%(2-4)$. Due to increasing $\mathrm{BC}$ incidence (including in younger women), increasing survival and the raising of the retirement age (5), the number of $\mathrm{BC}$ survivors expected to return to work (RTW) is raising and becoming a growing issue in $\mathrm{BC}$ care. Overall, about $40 \%$ of BC survivors are estimated to be of working age ( $<65$ years old) $(6)$.

RTW after BC is influenced by many factors, acting both as barriers and facilitators. These factors are linked to individual BC survivor characteristics such as age and education, cancer characteristics such as type and stage, treatment characteristics such as type of surgery and use of adjuvant chemotherapy, and the $\mathrm{BC}$ survivor's environment (family, workplace) $(7,8)$. Physical and cognitive limitations may impact ability to work $(9,10)$. Changes in the workplace during sick leave may mean that patients lose their bearings $(9,10)$ and increase negative feelings and anxiety (9-12). Qualitative surveys highlighted many uncertainties faced by $\mathrm{BC}$ survivors and emphasized changes in their career goals during and after active BC treatment $(9-11,13)$.

Furthermore, women report insufficient guidance from their healthcare practitioners on work-related issues $(11,13,14)$, and feel abandoned by the healthcare system at the end of their active treatment. Lack of communication between hospital and general practitioners (GP) during follow-up has also been reported, as well as lack of communication with occupational health services (15). These issues are likely to influence the RTW process $(16,17)$.

In the workplace, social support from colleagues and managers and job accommodation are positively associated with RTW rates and sustained employment after cancer $(7,18,19)$. Although interventions to promote RTW after BC have been developed, workplace involvement and job accommodation are rarely organized (2022). Coordination between hospital, community, and occupational physicians (OP) needs improving to fill the gap between the end of active treatment and RTW (13).

$\mathrm{BC}$ survivors meet various specialists during hospital-based treatment, usually in the following order: surgeons, medical oncologists, and radiation oncologists. In France, in addition to the compulsory RTW consultation at resumption of work, a pre-RTW consultation with the $\mathrm{OP}$ is mandatory for a sick leave of $>3$ months regardless of the underlying medical condition (23). This pre-RTW consultation, aiming to address the conditions of the resumption of work and possible adaptations needed, is organized as early as possible before the end of the sick leave on request by the patient himself or his/her treating physician. The $\mathrm{BC}$ specialist, in charge of prescribing the sick leave and evaluating the patient's ability to resume work from the oncology perspective, plays a major role in this process. However, only $37 \%$ of cancer patients who returned to their job and $14 \%$ of those who went to another job after cancer had such a consultation (24). This suggests a lack of referral to the OP and potential lack of commitment of cancer specialists regarding RTW issues for BC survivors. Although RTW after (breast) cancer has been previously explored from the patient, GP and workplace perspectives (25-28), the experience and perceptions of $\mathrm{BC}$ specialists on their role in RTW issues has been mostly unexplored.

The main objective of the present qualitative study was to explore the perspective of $\mathrm{BC}$ specialists regarding their perceived professional role toward the RTW needs of their BC patients. Secondary objectives were to identify barriers and facilitators for teamwork between $\mathrm{BC}$ specialists and GP and OP in the RTW process.

\section{Methods}

A qualitative approach with semi-structured interviews was adopted to explore BC specialists' point of view in depth. This qualitative study is part of the FASTRACS program conducted in France, which aims to develop a multi-component intervention to facilitate and sustain RTW after BC, following the six steps of the intervention mapping (IM) protocol $(29,30)$. The study is part of the first step, consisting of a health-needs assessment to develop a logic model of the problem and define intervention objectives. The results are expected to contribute to the subsequent steps of the IM protocol in order to develop, implement, and evaluate a multi-stage intervention involving $\mathrm{BC}$ specialists and other stakeholders in the RTW process. More specifically, these results will identify the behaviors of cancer specialists that should be modified by the intervention to facilitate the RTW process.

\section{Setting}

The study was conducted in the urban area of Lyon, France, which comprises three types of cancer-care facilities for 1.8 million inhabitants: a regional cancer center, a consortium of university public hospitals, and private hospitals. Approximately 1700 new BC cases are diagnosed each year in this area.

\section{Sampling}

A purposive sampling strategy was followed to include a balanced sample of participants intended to represent the variety of $\mathrm{BC}$ specialists, which patients encounter. Sampling criteria comprised gender, age, specialty (medical oncology, radiation oncology, and gyneco- 
logical surgery), and healthcare organization (regional cancer center, university hospital, and private hospital). The second author identified the first participants, who in turn identified other possible participants in a snowball progression. New participants were chosen and contacted on an ongoing basis according to the sampling criteria, until data saturation defined as the point at which interviews did not bring important additional information (31).

\section{Data collection}

Semi-structured interviews were preferred to focus groups so as to minimize the risk of dominant personalities and social desirability bias. An interview guide was drawn up based on the most common themes mentioned in literature reviews on RTW after (breast) cancer (10, 12), and on the clinical experience of the authors in medical oncology, general practice, and occupational medicine. All the researchers discussed the interview guide, and it was adjusted during the data collection process to modify wording and incorporate new important themes. The themes of the final interview guide are shown in table 1.

Two residents in general practice conducted the interviews ( $\mathrm{AK}$ and $\mathrm{CJ}$ ), following training by a senior researcher (JBF) who also discussed their field notes and interview transcriptions after each interview. All interviews were conducted face-to-face in the participant's usual work setting, between 22 December 2015 and 26 July 2016. Median duration was 43 minutes (range, 31-97 minutes). Data saturation was obtained after 20 interviews.

\section{Data analysis}

All interviews were audiotaped, transcribed verbatim, and pseudonymized for any information identifying person or place. Qualitative thematic content analysis was performed using the MAXQDA v11 (VERBI Software $\mathrm{GmbH}$, Berlin, Germany). Analysis first proceeded deductively, with a coding tree adapted from the themes of the interview guide. In a second step, new categories were created inductively to analyze data which did not fit the initial categories. Sub-categories were also created to refine the analysis of categories in which content was deemed too heterogeneous. Each interview was analyzed in depth (intra-case analysis) and summarized in a concise format that was used secondarily for transversal (intercase) analysis. Data saturation was reached progressively. After discussion, it was decided to stop the data collection after 20 interviews (31). At the end of the process, the researchers discussed the results with two participants, who recognized themselves in the results and provided more details that were included in the final results.
Table 1. Interview guide.

\section{Part 1: Introduction}

Usual conditions of practice (pathologies, recruitment, job tenure, job organization)

Personal interest in the study

Specificities of breast cancer care and patients

Part 2: Case presentation

Presentation of one or two selected cases, with reasons for choosing them

Part 3: Semi-structured themes

Managing cancer care and work (importance of patient's work for the physician, discussion about work with the patients, sick-leave prescription, treatment adaptations)

Side-effects of treatments (to what extent is the physician aware of side-effects, informs the patient about them, and questions the patient about them at follow-up visits)

Perceived women's needs about work

Experience of women returning to work (barriers and facilitators identified) Experience of women not returning to work (main barriers identified)

Experience of women continuing their work during cancer care

Role of other physicians (other oncologists, general practitioners, occupational physicians, social insurance physicians)

Role of other actors (nurse, physiotherapist, psychologist, social worker, workplace actors)

Part 4: Conclusion

Summary and identification of other potential participants

\section{Ethics}

No identifying patient information were accessed for the study. All participating physicians were provided with an information leaflet. Written informed consent was obtained from all participants. The study received local review board approval (IRB $n^{\circ} 00009118$ ).

\section{Results}

\section{Participants}

The characteristics of the 20 participants are presented in table 2. The sample was composed of 12 female and 8 male physicians, aged 30-39 (N=9), 40-49 $(\mathrm{N}=6)$ and $\geq 50$ years $(\mathrm{N}=5)$. They worked in public hospitals $(\mathrm{N}=9)$, private hospitals $(\mathrm{N}=5)$, or the regional cancer center $(\mathrm{N}=6)$. Their specialties were medical oncology $(\mathrm{N}=8)$, radiation oncology $(\mathrm{N}=6)$, and gynecological surgery $(\mathrm{N}=6)$.

\section{Various representations of the importance of work issues for the doctor-patient encounter}

The respondents offered diverse representations of the relevance of the patient's work and RTW issues in the doctor-patient encounter. They reported varying practices of how to address work issues with their patients, ranging from almost total absence of consideration to frequent discussions about the patient's work.

"But we are entirely involved in treatment in one 
Table 2. Characteristics of study participants. [BC=breast cancer; RCCC=regional cancer care center.]

\begin{tabular}{lrrlrc}
\hline Specialty & Gender & $\begin{array}{c}\text { Age } \\
\text { (years) }\end{array}$ & $\begin{array}{c}\text { Healthcare } \\
\text { facility }\end{array}$ & $\begin{array}{c}\text { Job tenure } \\
\text { (years) }\end{array}$ & $\begin{array}{c}\text { Proportion } \\
\text { (\%) of BC } \\
\text { patients }\end{array}$ \\
\hline Medical oncology & F & $30-39$ & RCCC & 2 & 60 \\
Medical oncology & $\mathrm{F}$ & $\geq 50$ & Private & 18 & 40 \\
Medical oncology & $\mathrm{F}$ & $30-39$ & Public & 3 & 70 \\
Medical oncology & $\mathrm{F}$ & $30-39$ & Public & 3 & 60 \\
Medical oncology & $\mathrm{F}$ & $30-39$ & Private & 2 & 80 \\
Medical oncology & $\mathrm{M}$ & $30-39$ & Public & 1 & 30 \\
Medical oncology & $\mathrm{M}$ & $30-39$ & RCCC & 7 & 70 \\
Medical oncology & $\mathrm{M}$ & $\geq 50$ & Public & 18 & 50 \\
Surgery & $\mathrm{F}$ & $40-49$ & RCCC & 12 & 100 \\
Surgery & $\mathrm{F}$ & $30-39$ & Public & 8 & 40 \\
Surgery & $\mathrm{M}$ & $30-39$ & RCCC & 3 & 70 \\
Surgery & $\mathrm{M}$ & $\geq 50$ & Private & 20 & 30 \\
Surgery & $\mathrm{M}$ & $40-49$ & Public & 2 & 50 \\
Surgery & $\mathrm{M}$ & $40-49$ & Public & 15 & 30 \\
Radiation oncology & $\mathrm{F}$ & $30-39$ & Public & 2 & 90 \\
Radiation oncology & $\mathrm{F}$ & $40-49$ & Public & 15 & 20 \\
Radiation oncology & $\mathrm{F}$ & $\geq 50$ & Private & 20 & 80 \\
Radiation oncology & $\mathrm{F}$ & $\geq 50$ & Private & 8 & 75 \\
Radiation oncology & $\mathrm{F}$ & $40-49$ & RCCC & 12 & 10 \\
Radiation oncology & $\mathrm{M}$ & $40-49$ & Public & 12 & 10 \\
\hline J & & & & \\
\hline
\end{tabular}

a Job tenure in the current healthcare facility.

way or another, or in prevention. And the relationship to work, almost never." (Surgeon)

"So, if you want to discuss this subject with patients, there are virtually permanent discussions." (Medical oncologist)

\section{Shared concerns}

There was no single approach to the timing and way to address work-related issues with patients. Surgeons tended to address the occupational consequences of specific techniques beforehand, or at follow-up in case of secondary breast reconstruction.

Medical oncologists reported raising work-related issues before or after chemotherapy but never during the chemotherapy itself. Radiation oncologists considered themselves to be in the best position to raise workrelated issues at the end of radiotherapy, deemed to constitute the end of "heavy treatment". Many participants shared concerns about the "right time and right way" to address RTW with their patients given the variety of individual situations.

"We don't really know how to situate return to work during patient care, (...) well, I find it difficult to decide when to talk about return to work and what resources are available and already set up to help the patients with that." (Medical oncologist)

\section{Perceived barriers, needs, and facilitators for RTW}

Perceived barriers, needs, and facilitators are listed in table 3 . The need for better continuity of care at the end of curative treatment was reported as being important.
Several respondents mentioned that $\mathrm{BC}$ patients asked for their permission before returning to work. $\mathrm{BC}$ specialists stated that, even if they could identify treatment side-effects, they did not ask their patients about their potential impact as barriers to return to work and sometimes minimize them.

"Well, with radiotherapy, there's no... Normally after a patient who has had breast irradiation, there's no problem for her to go back to work afterwards." (Radiation oncologist)

"No, no, I don't think I'm looking for them, the side-effects. You look for them (...) in daily activities. But specifically their impact on work, no." (Medical oncologist)

"So I'll ask her "Is there anything worrying you in your daily life?" But in terms of returning to work... [Coughing]. No, to be honest, no." (Surgeon)

Physical demands of the job, psychological pressure, and adversarial relations in the workplace were hardly mentioned as potential barriers to RTW. The influence of pain, anxiety, or depressive disorders as potential barriers to RTW was rarely mentioned. While the physicians emphasized the importance of social support from colleagues and employers (table 3 ), the possible role of the $\mathrm{OP}$ in this respect was never mentioned.

\section{Professional practices of $\mathrm{BC}$ specialists}

$\mathrm{BC}$ specialists reported a lack of opportunity to discuss work-related issues of their patients. Work and RTW issues were never on the agenda of the weekly multidisciplinary meeting, which was exclusively dedicated to treatment issues.

[Concerning other oncologists]: "No, very rarely, because we're entirely on the, concerned about, like, managing the disease and treatments." (Medical oncologist)

"But it's true we don't talk about it. (...) It's true that it's not an issue." (Radiation oncologist)

Most respondents agreed as to the importance of the GP and OP regarding RTW. However, they were unable to say precisely what role they could have. They reported mentioning them to their patients as possible contact persons for RTW issues. However, they themselves never took the initiative to contact the OP or GP, except for one medical oncologist.

"(...) but, the question of returning to work, quite honestly, we don't even discuss it with the social worker." (Medical oncologist)

Overall, BC specialists described their role as dedicated to cancer care and cure, predominantly as technical expertise, leaving little room for psychological or survivorship issues. There was no difference in this regard between surgeons, medical oncologists, and radiation oncologists. 
Table 3. Perceived barriers, needs, and facilitators for breast cancer survivors to return to work (RTW).

\begin{tabular}{|c|c|}
\hline & Breast cancer specialists' quotes \\
\hline \multicolumn{2}{|l|}{ Barriers (side-effects of treatment) } \\
\hline $\begin{array}{l}\text { Chemotherapy (sick leave duration, } \\
\text { fatigue, chemically induced menopause, } \\
\text { cognitive impairment) }\end{array}$ & $\begin{array}{l}\text { "About return, let's say... And patients who've had chemo, you can see they're still, er, aff... like, they have a, quote } \\
\text { sequela unquote of the chemotherapy that lasts all the same long after the end of chemotherapy and they have dif- } \\
\text { ficulty returning to work." }\end{array}$ \\
\hline & $\begin{array}{l}\text { "I went back but, anybody says anything I have to note it all down. They know I forget, so they repeat. Er, well, like, } \\
\text { then it's also things colleagues, er, some of them, it goes okay, others, it's complicated." (Medical oncologist) }\end{array}$ \\
\hline Mastectomy & $\begin{array}{l}\text { "I think, well, there's, in my opinion, it's mainly, er, mastectomy, in my opinion. So there, the severity of surgical treat- } \\
\text { ment, in my opinion, going to affect, in my opinion like." }\end{array}$ \\
\hline \multicolumn{2}{|l|}{ Facilitators } \\
\hline Patients' personal motivation & $\begin{array}{l}\text { "Someone who's got their head screwed on, who's dynamic, wants to move forward, (...) she'll go for it, (...). And then } \\
\text { there is the one who's more looking at herself, and then, impossible to do anything, even if she actually didn't have } \\
\text { anything, huh. So, uh, that's almost the most important thing." }\end{array}$ \\
\hline Physical activity programs & $\begin{array}{l}\text { "And it's true, this program, it helps us all the same a lot to get rid of the post-treatment tiredness and encourage the } \\
\text { patients to go back to work again." }\end{array}$ \\
\hline Adaptations of treatment organization & $\begin{array}{l}\text { "Often for patients who want to work I put their chemotherapy treatment on Thursdays so that on Fridays they don't } \\
\text { work, they have Saturday, Sunday and finally on Monday they can get back, uh, a bit better and it, and it was okay." } \\
\text { (Medical oncologist) }\end{array}$ \\
\hline $\begin{array}{l}\text { Workplace adaptations (job a } \\
\text { ccommodation, part-time work, } \\
\text { entitlement as disabled worker) }\end{array}$ & $\begin{array}{l}\text { "But I find that a lot, they, they've taken account, they could plan for it, they could talk about it before, even, er, yeah, } \\
\text { adapting the work time, but er they, they don't mention it either. Er, like, if sometimes they do say, they say, yes, they } \\
\text { helped me at the workplace." }\end{array}$ \\
\hline $\begin{array}{l}\text { Social support from colleagues and } \\
\text { employer }\end{array}$ & $\begin{array}{l}\text { "So, when they've, colleagues have listened, understood, empathized, and well they want to go back obviously, when } \\
\text { the work time is adjusted, I mean the, the work, and er, they want to go back more easily than when they don't feel } \\
\text { well with their work." (Surgeon) }\end{array}$ \\
\hline \multicolumn{2}{|r|}{ 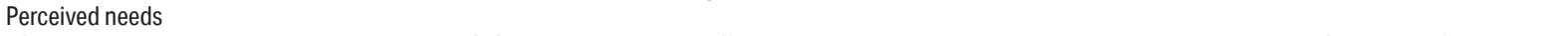 } \\
\hline Cognitive rehabilitation programs & $\begin{array}{l}\text { "(...) something based on effort rehabilitation and also, er, at the, er, intellectual level, like. Some kind of gymnastics, } \\
\text { er to get used to working again, to concentrate, er, so." (Surgeon) }\end{array}$ \\
\hline Material support in family life & $\begin{array}{l}\text { "Er, and I think yes there's, to have something organized around that, around a, a support, er, for a while on house- } \\
\text { work and on, er, anything to do with work." }\end{array}$ \\
\hline Time for self before returning to work & $\begin{array}{l}\text { "end of treatment because, because they needed well to, to look after her, do sport, look after the family, travel, you } \\
\text { see, that it was the time for her to do that, like." }\end{array}$ \\
\hline $\begin{array}{l}\text { Better continuity of care at end of curative } \\
\text { treatments }\end{array}$ & $\begin{array}{l}\text { "When you stop treatment (...) there are patients who feel a little abandoned, because they suddenly go from over- } \\
\text { medicalization (...) to no more medicalization at all." }\end{array}$ \\
\hline $\begin{array}{l}\text { Breast cancer specialists' permission } \\
\text { before returning to work }\end{array}$ & "They ask me if they can go back to work, always." (Medical oncologist) \\
\hline
\end{tabular}

"(...) we are entirely involved in the management of the disease and treatment." (Surgeon)

"That is, once the chemo is over, the radiotherapy is over, the surgery has been done, so the person is supposed to get back to normal life, and for us the work has been done" (Medical oncologist)

Lack of time, lack of training and sometimes lack of interest were mentioned about patients' work-related issues. Several respondents expressed their inability to meet the work-related expectations of $\mathrm{BC}$ patients.

"Well, you see, it's complicated, because at the same time, we have to tie up the health aspect; they ask us questions about the prognosis for their disease. And at the same time, we have to answer about work, the legal aspect, which we are not necessarily familiar with either, you see." (Medical oncologist)

\section{Ways to improve BC specialists' involvement in survivors' return to work}

The main barriers to the involvement of BC specialists in their patients' RTW issues included (i) lack of time, (ii) lack of knowledge, especially regarding RTW procedures and legislation, (iii) the potential barriers to RTW, (iv) the role of the various actors involved in the RTW process, particularly GP and OP, (v) lack of awareness of the importance of work to their patients, and (vi) a professional attitude exclusively focused on care and cure objectives.

The participants offered no practical solutions to the removal of these barriers. Only one medical oncologist mentioned the possibility of integrating work-related issues in the personalized treatment plan of the patients.

"Maybe we should say: "So, then, about three or four months after the end of the radiotherapy, you should get back to work, well considering that could be as a therapeutic half-time, but we'll talk about it again, it's much too early, first of all let's start the treatment, you need to be on the road to recovery first." (Medical oncologist)

\section{$\mathrm{BC}$ specialists' views according to gender and medical specialty}

All the respondents expressed an interest in the study and willingly shared their personal limitations regarding RTW in cancer patients during the interviews. None expressed negative feelings about the risk of being judged or stigmatized. No specificities were identified in 
terms of respondents' age or type of healthcare facility.

"I think what is interesting about this study is that it raises questions that I think are untypical. In any case untypical (...) for a cancer specialist who is used to (...) being immersed in a cancer research environment. Because precisely (...) the theme (...) is not directly the one we deal with on a daily basis, which is optimizing patient treatment." (Medical oncologist)

Female and male BC specialists sometimes expressed different views. Female specialists said they participated in the study due to a desire to improve their practice, whereas male participants rather expressed their interest in scientific research. Females particularly stressed BC survivors' need for cognitive rehabilitation. Only females mentioned the patients' need to take some time for themselves, to have treatment schedules adapted to their occupational needs, and the fact that they encounter barriers in the workplace due to physical demands or psychological pressure. Males, in contrast, stressed the importance of the patient's personal motivation and temperament in RTW.

BC specialists minimized the side-effects of the treatments they prescribed, ie, medical oncologists understated the side-effects of chemotherapy, whereas radiation oncologists minimized the side-effects of radiotherapy. During feedback with two interviewees, this finding was confirmed and commented on in terms of medical liability.

"Afterwards, what's true, and it's really true, in oncology, it's never your fault, when a patient has a symptom, it's always the other specialist's fault. Always." (Medical oncologist)

"And there, I think, there's also a forensic problem. You can't be responsible for a problem, uh, the patient has... because in the last analysis, there's the insurance, you know." (Medical oncologist)

\section{Discussion}

\section{Main findings}

While there is a growing body of studies on RTW issues in cancer patients, the present study is to the best of our knowledge the first specifically to examine BC specialists' perspective on their role in BC survivors' RTW. This qualitative study revealed varying attitudes and practices in $\mathrm{BC}$ specialists regarding the relevance of work and return to work issues in the doctor-patient relationship and their role in the patients RTW process. Overall, the $\mathrm{BC}$ specialists perceived their role as limited and mainly restricted to management of disease and treatmentrelated side effects. Participants unanimously expressed difficulties in supporting BC survivors in their RTW in collaboration with GP and OP. The participants consistently identified the following main obstacles: lack of time and awareness of the importance of work for their patients, lack of skills and personal efficacy, as well as professional practices centered on treatment and cure, leaving little room for psychological and occupational issues. Despite these recognized difficulties, specialists also stressed that BC survivors frequently asked them for advice before returning to work.

\section{Barriers and facilitators in the RTW process}

Certain participants mentioned treatment side-effects and sequelae as obstacles to RTW, in agreement with the literature $(14,32)$. Others, however, minimized this and in their consultations did not assess the occupational impact of cancer and treatment, consistent with other reports (33). The majority, on the other hand, cited the determining role of the patient's personality in the RTW process. Factors relating to the workplace environment were rarely mentioned, despite the scientific evidence, especially in case of cognitive disorder or lymphedema limiting work ability (32).

\section{BC specialists' working environment, training, and profes-} sional role

The present study found a mismatch between BC specialists' practices and their patients' expectations in terms of support needed in the RTW process following $\mathrm{BC}$ (34). This is in line with other reports stating that $\mathrm{BC}$ specialists fail to take account of a variety of cancer survivors' needs including, their occupational concerns $(5,28,35-40)$. This may be related to factors concerning BC specialists' working environment and medical training. It also raises the question of whether $\mathrm{BC}$ specialists should take on a more supportive role in the RTW process.

The working environment of BC survivors is characterized by an insufficient number of professionals to manage an increasing number of complex patients requiring individualized treatments (41). Treatments are so heavy that RTW may seem to be a secondary consideration. At the same time, patient information requires more time and attention, resulting in severe time limits, with an average consultation time that is too short to deal with anything unrelated to diagnosis, disease, prognosis, treatment and treatment options, and side-effects. Moreover, current guidelines and personalized post-cancer plans make no mention of occupational factors among the various fields the $\mathrm{BC}$ specialist is supposed to deal with, even though the guidelines do acknowledge maintenance of employment as a major post-cancer issue $(42,43)$. Finally, mean age at BC diagnosis is around 61 years, so that many patients are 
not concerned by occupational questions $(6,44)$. It would thus seem that $\mathrm{BC}$ specialists' practices depend on aspects of their working environment and patient characteristics. Yet, the increase of younger women with $\mathrm{BC}$, increased $\mathrm{BC}$ survival as well as growing female employment rates and raising retirement age in many countries is leading to a change in $\mathrm{BC}$ patient profile with an increasing number of $\mathrm{BC}$ survivors concerned by RTW issues $(5,45,46)$.

BC specialists' initial and continuous training focuses on diagnosis, prognosis, and treatment, with ever increasing technicity, especially in the fields of imaging, biology, and precision medicine. The psychological, social and occupational impact of cancer is little dealt with. This results in lack of knowledge of conditions and legislation regarding work and the various actors and provisions that can be brought into play to facilitate RTW. It also results in a lack of competence to deal with patients' occupational issues, and a perceived lack of self efficacy in this regard, which could explain why participants did not mention factors related to their patients' working environment as barriers to RTW. Hence, the lack of consideration of RTW issues may be related more to the general barriers in the delivery of psychosocial care to cancer survivors as well as the lack of consideration for psychosocial issues by the healthcare system $(28,40)$. The lack of RTW help was among the numerous unmet psychological needs identified by cancer patients $(22,39,40)$, and inter-relationships exists among poor psychosocial well-being and lower rates of return to work and/or impaired ability to work in cancer survivors $(9,22)$.

The present findings also point to a lack of communication between $\mathrm{BC}$ specialists and other professionals, such as GP, OP and social workers, regarding BC survivors' RTW. This is doubtless multifactorial, involving a lack of time on all sides and insufficient training, habits, and value attached to multidisciplinary teamwork beyond cancer treatment (47). While the communication among healthcare professionals for cancer survivor follow-up, as well as the role of communication between occupational health, employers and colleagues to managing RTW has been identified as key in the cancer survivor in the literature $(28,37,48,49)$, the communication between $\mathrm{BC}$ specialists and other professionals regarding RTW has not received much attention. The follow-up of cancer survivors involves different healthcare professionals and the transition from hospital to primary care faces various barriers, including communication but also sometimes patient preference (50). Consistent with the results from our study, GPs have identitied the lack of communication and information from $\mathrm{BC}$ specialists in the hospital as a barrier to appropriately advice patients on RTW, resulting in sometimes conflicting guidance (28). In the specific field of occupational rehabilitation after cancer, the gap between hospital and community physicians is accentuated by the lack of guidelines as to respective professional roles and the articulation with occupational health services in facilitating RTW $(28,37,49)$. These findings are applicable across numerous developed countries, leading to the need of improving collaboration and communication between hospital, community, and occupational professionals to improve continuity of care and adequate RTW guidance for cancer patients $(28,37,50-53)$. In accordance with what has been suggested for cancer survivor care more generally, this role should be played by (health) professionals other than BC specialists $(37,49-51,54)$ as has been suggested, $\mathrm{BC}$ specialists' training and working environment are combined to place them in a difficult position to advise patients on RTW. Despite their patients' expectations (14), they are neither sufficiently trained nor well placed to provide RTW advice themselves. Their professional role focusses the priority on cure and prevention of recurrence, in the context of high demand to keep their knowledge up to date and keep patients informed despite severe lack of time and increasing workload $(41,43)$.

\section{Implications for healthcare practice and organization}

The barriers identified do not seem to be specifically related to the French healthcare system and are in line with findings from other countries $(28,37,52-54)$. Lack of communication among healthcare professionals, insufficient knowledge about work-related concerns, and limited resources were recurring themes in these studies.

Better integration of RTW issues in the management of $\mathrm{BC}$ patients requires better definitions of healthcare professionals' respective roles. Overcoming the barriers between hospital, community medicine, and occupational health requires improving communication and collaboration so as to improve continuity of care, rehabilitation, and RTW. While the role of BC specialists is limited by the many demands and workload related to cancer care, they should have a determining role in informing their patients of the importance of work in the recovery process and the persons and resources available to help them with this, as well as transmitting the relevant information to other healthcare providers, such as the patient's GP (28), to ensure continuity of care.

The present study's results suggest several means of improving $\mathrm{BC}$ specialists' practices in the support to RTW. Our results point out the need to enhance BC specialists' awareness and knowledge by means of targeted information on the importance of work for their patients and of the roles of the different professionals $(52,53)$; this in turn will enhance their self-efficacy and may lead to a change in behavior. As regards their working environment, finding more time to address 
RTW may be unrealistic, but guidelines and tools as a support to inform patients and enhance liaison with other professionals could usefully be developed. Also, means of remuneration for collaboration between the different professionals of this orphan issue in the current cancer care process should be explored.

\section{Perspectives for integration in FASTRACS}

The results from this study contributed to designing the FASTRACS RTW multicomponent intervention, in particular the steps of intervention mapping and setting up behavioral change matrices by helping to formulate performance objectives for behaviors to be encouraged in $\mathrm{BC}$ specialists (55). The first target for the $\mathrm{BC}$ specialists is to provide a minimum of advice to patients regarding the importance of RTW for recovery from cancer, relevant resource persons and the usefulness of calling upon these resource persons (GP, OP, social worker, and RTW counsellors). The second is to refer the patient at the end of radiation therapy to a transitional consultation with their GP with a specific liaison letter. According to the logic model of the problem (55), the next step is for the GP to refer the patient to a pre-RTW consultation with an OP to assess work ability and adapt working conditions and time so as to facilitate RTW.

\section{Study strengths and limitations}

The strong point of the study lies in the measures taken to ensure validity according to the criteria implemented in qualitative research (56). Sampling enabled the research topic to be explored by varying participant characteristics and work contexts. Triangulation of researchers' disciplines (medicine, psychology, public health) was implemented at the design stage of the study topic, in drawing up the interview guide, and in analyzing and interpreting the results. Qualitative analysis software ensured the traceability of the analysis process and facilitated triangulation. Feedback from two participants corroborated and completed the researchers' interpretation. Data saturation was achieved progressively, with no significant new input during the last interviews. A logbook was updated by the two researchers who collected the data, enabling the non-verbal dimension and context to be included in analysis.

The qualitative approach does not allow the present results to be considered representative of the practices of $\mathrm{BC}$ specialists as a whole. For them to be extrapolated, surveys of practice in larger representative samples will be needed, notably to confirm whether differences according to gender are real.

That interviews were conducted by two junior investigators may have impaired the richness of the data. This risk was limited by close supervision by one senior investigator. This particularity also had the advantage of reducing social desirability bias and perceived risk of being judged by a peer or senior researcher.

Extrapolation to contexts other than the French health system can only be made in the light of the specificities of the various systems. Barriers and facilitators to RTW after BC and the characteristics of cancer specialists' working environment are similar in many health systems; some countries, however, may have developed specific measures and organizational features to enhance specialists' involvement in accompanying RTW after cancer $(57,58)$.

\section{Concluding remarks}

The present qualitative survey of $20 \mathrm{BC}$ specialist identified several limitations in their practice regarding accompaniment of RTW. These concerned individual characteristics but also medical training and restrictions in their working environment. Larger-scale surveys will be needed in order to describe more precisely BC specialists' RTW-related practices, their determining factors, and possible means of improvement. Any improvements must be integrated in the organization of healthcare so as to benefit all patients. This is the aim of the FASTRACS project: to develop an intervention to facilitate RTW after BC at the level of the AuvergneRhône-Alpes region of France.

\section{Ethical approval}

All procedures performed in studies involving human participants were in accordance with the ethical standards of the institutional review board (nº IRB 00009118) and the 1964 Helsinki Declaration and its later amendments or comparable ethical standards.

Informed consent was obtained from all individual participants included in the study, before taking part of the study.

\section{Acknowledgement}

This work was supported by grants from CLARA (Cancéropole Lyon Auvergne Rhône Alpes), INCa (Institut National du Cancer), Métropole de Lyon, CRPCEN (Caisse de retraite et de prévoyance des clercs et employés de notaires) and DIRECCTE AuvergneRhône-Alpes. 


\section{References}

1. Bray F, Ferlay J, Soerjomataram I, Siegel RL, Torre LA, Jemal A. Global cancer statistics 2018: GLOBOCAN estimates of incidence and mortality worldwide for 36 cancers in 185 countries. CA Cancer J Clin 2018 Nov;68(6):394-424. https://doi.org/10.3322/caac.21492.

2. Cowppli-Bony A, Uhry Z, Remontet L, Voirin N, Guizard AV, Trétarre B et al.; French Network of Cancer Registries (FRANCIM). Survival of solid cancer patients in France, 1989-2013: a population-based study. Eur J Cancer Prev 2017 Nov;26(6):461-8. https://doi.org/10.1097/ CEJ.0000000000000372.

3. Sant M, Chirlaque Lopez MD, Agresti R, Sánchez Pérez MJ, Holleczek B, Bielska-Lasota M, et al. Survival of women with cancers of breast and genital organs in Europe 1999-2007: Results of the EUROCARE-5 study. 2015;51(15):2191-205.

4. Allemani C, Matsuda T, Di Carlo V, Harewood R, Matz M, Nikšić M et al.; CONCORD Working Group. Global surveillance of trends in cancer survival 200014 (CONCORD-3): analysis of individual records for 37513025 patients diagnosed with one of 18 cancers from 322 population-based registries in 71 countries. Lancet 2018 Mar;391(10125):1023-75. https://doi.org/10.1016/S01406736(17)33326-3.

5. Bradley CJ, Brown KL, Haan M, Glasgow RE, Newman LS, Rabin B et al. Cancer Survivorship and Employment: Intersection of Oral Agents, Changing Workforce Dynamics, and Employers' Perspectives. J Natl Cancer Inst 2018 Dec;110(12):1292-9. https://doi.org/10.1093/jnci/ djy172.

6. Parry C, Kent EE, Mariotto AB, Alfano CM, Rowland JH. Cancer survivors: a booming population. Cancer Epidemiol Biomarkers Prev 2011 Oct;20(10):1996-2005. https://doi. org/10.1158/1055-9965.EPI-11-0729.

7. Islam T, Dahlui M, Majid HA, Nahar AM, Mohd Taib NA, Su TT; MyBCC study group. Factors associated with return to work of breast cancer survivors: a systematic review. BMC Public Health 2014;14 Suppl 3:S8. https://doi. org/10.1186/1471-2458-14-S3-S8.

8. van Muijen P, Weevers NL, Snels IA, Duijts SF, Bruinvels DJ, Schellart AJ et al. Predictors of return to work and employment in cancer survivors: a systematic review. Eur J Cancer Care (Engl) 2013 Mar;22(2):144-60. https://doi. org/10.1111/ecc. 12033 .

9. Duijts SF, van Egmond MP, Spelten E, van Muijen P, Anema JR, van der Beek AJ. Physical and psychosocial problems in cancer survivors beyond return to work: a systematic review. Psychooncology 2014 May;23(5):48192. https://doi.org/10.1002/pon.3467.

10. Tiedtke C, de Rijk A, Dierckx de Casterlé B, Christiaens MR, Donceel P. Experiences and concerns about 'returning to work' for women breast cancer survivors: a literature review. Psychooncology $2010 \mathrm{Jul}$;19(7):677-83. https://doi. org/10.1002/pon.1633.
11. Banning M. Employment and breast cancer: a metaethnography. Eur J Cancer Care (Engl) 2011 Nov;20(6):70819. https://doi.org/10.1111/j.1365-2354.2011.01291.x.

12. Wells M, Williams B, Firnigl D, Lang H, Coyle J, Kroll T et al. Supporting 'work-related goals' rather than 'return to work' after cancer? A systematic review and metasynthesis of 25 qualitative studies. Psychooncology 2013 Jun;22(6):1208-19. https://doi.org/10.1002/pon.3148.

13. Stergiou-Kita M, Grigorovich A, Tseung V, Milosevic E, Hebert D, Phan S et al. Qualitative meta-synthesis of survivors' work experiences and the development of strategies to facilitate return to work. J Cancer Surviv 2014 Dec;8(4):657-70. https://doi.org/10.1007/s11764-0140377-z.

14. Tamminga SJ, de Boer AG, Verbeek JH, Frings-Dresen $\mathrm{MH}$. Breast cancer survivors' views of factors that influence the return-to-work process--a qualitative study. Scand J Work Environ Health 2012 Mar;38(2):144-54. https://doi. org/10.5271/sjweh.3199.

15. Taskila T, Lindbohm ML, Martikainen R, Lehto US, Hakanen J, Hietanen P. Cancer survivors' received and needed social support from their work place and the occupational health services. Support Care Cancer 2006 May;14(5):427-35. https://doi.org/10.1007/s00520-0050005-6.

16. Hansen DG, Larsen PV, Holm LV, Rottmann N, Bergholdt $\mathrm{SH}$, Søndergaard J. Association between unmet needs and quality of life of cancer patients: a population-based study. Acta Oncol 2013 Feb;52(2):391-9. https://doi.org/10.3109/ 0284186X.2012.742204.

17. Willems RA, Bolman CA, Mesters I, Kanera IM, Beaulen AA, Lechner L. Cancer survivors in the first year after treatment: the prevalence and correlates of unmet needs in different domains. Psychooncology 2016 Jan;25(1):51-7. https://doi.org/10.1002/pon.3870.

18. Nilsson MI, Petersson LM, Wennman-Larsen A, Olsson M, Vaez M, Alexanderson K. Adjustment and social support at work early after breast cancer surgery and its associations with sickness absence. Psychooncology 2013 Dec;22(12):2755-62. https://doi.org/10.1002/pon.3341.

19. Torp S, Nielsen RA, Gudbergsson SB, Dahl AA. Worksite adjustments and work ability among employed cancer survivors. Support Care Cancer 2012 Sep;20(9):2149-56. https://doi.org/10.1007/s00520-011-1325-3.

20. Bilodeau K, Tremblay D, Durand MJ. Exploration of returnto-work interventions for breast cancer patients: a scoping review. Support Care Cancer 2017 Jun;25(6):1993-2007. https://doi.org/10.1007/s00520-016-3526-2.

21. de Boer AG, Taskila TK, Tamminga SJ, Feuerstein M, Frings-Dresen $\mathrm{MH}$, Verbeek JH. Interventions to enhance return-to-work for cancer patients. Cochrane Database Syst Rev 2015 Sep;(9):CD007569.

22. Sun Y, Shigaki CL, Armer JM. Return to work among breast cancer survivors: A literature review. Support Care Cancer 2017 Mar;25(3):709-18. https://doi.org/10.1007/s00520016-3446-1. 
23. Petit A, Rozenberg S, Fassier JB, Rousseau S, Mairiaux P, Roquelaure Y. Pre-return-to-work medical consultation for low back pain workers. Good practice recommendations based on systematic review and expert consensus. Ann Phys Rehabil Med 2015 Oct;58(5):298-304. https://doi. org/10.1016/j.rehab.2015.08.001.

24. Ligue contre le cancer. Observatoire sociétal des cancers: Rapport 2013. Available from: https://www.ligue-cancer.net/ sites/default/files/rapport-2013-observatoire-societal-descancers.pdf.

25. Amir Z, Popa A, Tamminga S, Yagil D, Munir F, de Boer A. Employer's management of employees affected by cancer. Support Care Cancer 2018 Mar;26(3):681-4. https://doi. org/10.1007/s00520-017-3998-8.

26. Grunfeld EA, Low E, Cooper AF. Cancer survivors' and employers' perceptions of working following cancer treatment. Occup Med (Lond) 2010 Dec;60(8):611-7. https://doi.org/10.1093/occmed/kqq143.

27. Tiedtke CM, Dierckx de Casterlé B, Frings-Dresen MH, De Boer AG, Greidanus MA, Tamminga SJ et al. Employers' experience of employees with cancer: trajectories of complex communication. J Cancer Surviv 2017 Oct;11(5):562-77. https://doi.org/10.1007/s11764017-0626-z.

28. de Jong F, Frings-Dresen MH, Dijk NV, van EttenJamaludin FS, van Asselt KM, de Boer AG. The role of the general practitioner in return to work after cancer-a systematic review. Fam Pract 2018 Sep;35(5):531-41. https://doi.org/10.1093/fampra/cmx114.

29. Bartholomew Eldredge K, Markham CM, Ruiter RA, Fernandez M, Kok G, Parcel G. Planning Health Promotion Programs: An Intervention Mapping Approach. 4th ed: JosseyBass; 2016. p. 704

30. Bartholomew LK, Parcel GS, Kok G. Intervention mapping: a process for developing theory- and evidence-based health education programs. Health Educ Behav 1998 Oct;25(5):54563. https://doi.org/10.1177/109019819802500502.

31. Saunders B, Sim J, Kingstone T, Baker S, Waterfield J, Bartlam B et al. Saturation in qualitative research: exploring its conceptualization and operationalization. Qual Quant 2018;52(4):1893-907. https://doi.org/10.1007/s11135-0170574-8.

32. Wang L, Hong BY, Kennedy SA, Chang Y, Hong CJ, Craigie $\mathrm{S}$ et al. Predictors of Unemployment After Breast Cancer Surgery: A Systematic Review and Meta-Analysis of Observational Studies. J Clin Oncol 2018 Jun;36(18):186879. https://doi.org/10.1200/JCO.2017.77.3663.

33. Braybrooke JP, Mimoun S, Zarca D, Elia D, Pinder B, Lloyd AJ et al. Patients' experiences following breast cancer treatment: an exploratory survey of personal and work experiences of breast cancer patients from three European countries. Eur J Cancer Care (Engl) 2015 Sep;24(5):650-61. https://doi.org/10.1111/ecc.12222.

34. Tiedtke C, de Rijk A, Dierckx de Casterlé B, Christiaens MR, Donceel P. Experiences and concerns about 'returning to work' for women breast cancer survivors: a literature review. Psychooncology 2010 Jul;19(7):677-83. https://doi. org/10.1002/pon.1633.

35. Whitney RL, Bell JF, Reed SC, Lash R, Bold RJ, Kim KK et al. Predictors of financial difficulties and work modifications among cancer survivors in the United States. J Cancer Surviv 2016 Apr;10(2):241-50. https://doi.org/10.1007/ s11764-015-0470-y.

36. What does survivorship mean? Let us explain it to you. ESMO Patient Guide Series based on the ESMO Clinical Practice Guidelines 2019.

37. Kiasuwa Mbengi R, Otter R, Mortelmans K, Arbyn M, Van Oyen $\mathrm{H}$, Bouland $\mathrm{C}$, et al. Barriers and opportunities for return-to-work of cancer survivors: time for action-rapid review and expert consultation. Syst Rev. 2016 Feb 24;5:35. https://10.1186/s13643-016-0210-z.

38. Rauh S, Antonuzzo A, Bossi P, Eckert R, Fallon M, Fröbe A et al. Nutrition in patients with cancer: a new area for medical oncologists? A practising oncologist's interdisciplinary position paper. ESMO Open 2018 May;3(4):e000345. https://doi.org/10.1136/esmoopen-2018-000345.

39. Burg MA, Adorno G, Lopez ED, Loerzel V, Stein K, Wallace $\mathrm{C}$ et al. Current unmet needs of cancer survivors: analysis of open-ended responses to the American Cancer Society Study of Cancer Survivors II. Cancer 2015 Feb;121(4):623-30. https://doi.org/10.1002/cncr.28951.

40. Kline RM, Arora NK, Bradley CJ, Brauer ER, Graves DL, Lunsford NB et al. Long-Term Survivorship Care After Cancer Treatment - Summary of a 2017 National Cancer Policy Forum Workshop. J Natl Cancer Inst 2018 Dec;110(12):1300-10. https://doi.org/10.1093/jnci/djy176.

41. Fundytus A, Sullivan R, Vanderpuye V, Seruga B, Lopes G, Hammad N et al. Delivery of Global Cancer Care: An International Study of Medical Oncology Workload. J Glob Oncol 2018 Sep;(4):1-11. https://doi.org/10.1200/ JGO.17.00126.

42. Runowicz CD, Leach CR, Henry NL, Henry KS, Mackey HT, Cowens-Alvarado RL et al. American Cancer Society/ American Society of Clinical Oncology Breast Cancer Survivorship Care Guideline. CA Cancer J Clin 2016 JanFeb;66(1):43-73. https://doi.org/10.3322/caac.21319.

43. Survivorship. Version 2: NCCN Clinical Practice Guidelines in Oncology; 2018.

44. de Moor JS, Mariotto AB, Parry C, Alfano CM, Padgett L, Kent EE et al. Cancer survivors in the United States: prevalence across the survivorship trajectory and implications for care. Cancer Epidemiol Biomarkers Prev 2013 Apr;22(4):561-70. https://doi.org/10.1158/1055-9965. EPI-12-1356.

45. Killingsworth MR, Heckman JJ. Female labor supply: A survey. Handbook of labor economics. 1986;1:103-204.

46. Long-run perspective on female labor force participation rates. Available from: https://ourworldindata.org/grapher/femalelabor-force-participation-oecd?time $=1890.2016$

47. Stegmann ME, Meijer JM, Nuver J, Havenga K, Hiltermann 
TJ, Maduro JH et al. Correspondence between primary and secondary care about patients with cancer: A qualitative mixed-methods analysis. Eur J Cancer Care (Engl) 2019 Jan;28(1):e12903. https://doi.org/10.1111/ecc.12903.

48. van Maarschalkerweerd PE, Schaapveld M, Paalman $\mathrm{CH}$, Aaronson NK, Duijts SF. Changes in employment status, barriers to, and facilitators of (return to) work in breast cancer survivors 5-10 years after diagnosis. Disabil Rehabil 2019 Mar;1-7. https://doi.org/10.1080/09638288.2019.158 3779 .

49. Overholser LS, Callaway C. Preventive Health in Cancer Survivors: What Should We Be Recommending? J Natl Compr Canc Netw 2018 Oct;16(10):1251-8. https://doi. org/10.6004/jnccn.2018.7083.

50. Nekhlyudov L, O'malley DM, Hudson SV. Integrating primary care providers in the care of cancer survivors: gaps in evidence and future opportunities. Lancet Oncol 2017 Jan;18(1):e30-8. https://doi.org/10.1016/S14702045(16)30570-8.

51. Meiklejohn JA, Mimery A, Martin JH, Bailie R, Garvey G, Walpole ET et al. The role of the GP in follow-up cancer care: a systematic literature review. J Cancer Surviv 2016 Dec;10(6):990-1011. https://doi.org/10.1007/s11764-0160545-4.

52. Wada K, Ohtsu M, Aizawa Y, Tanaka H, Tagaya N, Takahashi M. Awareness and behavior of oncologists and support measures in medical institutions related to ongoing employment of cancer patients in Japan. Jpn J Clin Oncol 2012 Apr;42(4):295-301. https://doi.org/10.1093/jjco/ hyr202.
53. Akahane K, Tsunoda N, Murata T, Fujii M, Fuwa Y, Wada $\mathrm{K}$ et al. An awareness survey of surgeons involved in breast cancer treatment regarding their patients returning to work. Nagoya J Med Sci 2014 Aug;76(3-4):315-22.

54. Morrison T, Thomas R, Guitard P. Physicians' perspectives on cancer survivors' work integration issues. Can Fam Physician 2015 Jan;61(1):e36-42.

55. Fassier JB, Lamort-Bouché M, Broc G, Guittard L, Péron $\mathrm{J}$, Rouat $\mathrm{S}$ et al. Developing a Return to Work Intervention for Breast Cancer Survivors with the Intervention Mapping Protocol: Challenges and Opportunities of the Needs Assessment. Front Public Health 2018 Feb;6:35. https://doi. org/10.3389/fpubh.2018.00035.

56. Tong A, Sainsbury P, Craig J. Consolidated criteria for reporting qualitative research (COREQ): a 32-item checklist for interviews and focus groups. Int J Qual Health Care 2007 Dec;19(6):349-57. https://doi.org/10.1093/intqhe/mzm042.

57. Ullrich A, Rath HM, Otto U, Kerschgens C, Raida M, Hagen-Aukamp $\mathrm{C}$ et al. Return to work in prostate cancer survivors - findings from a prospective study on occupational reintegration following a cancer rehabilitation program. BMC Cancer 2018 Jul;18(1):751. https://doi. org/10.1186/s12885-018-4614-0.

58. Wienert J, Schwarz B, Bethge M. Effectiveness of workrelated medical rehabilitation in cancer patients: study protocol of a cluster-randomized multicenter trial. BMC Cancer 2016 Jul;16:544. https://doi.org/10.1186/s12885$016-2563-\mathrm{z}$

Received for publication: 10 May 2019 